\title{
EFEITOS DE ACORDOS COMERCIAIS SOBRE A INTEGRAÇÃO DE PREÇOS DO ALGODÃO NOS MERCADOS INTERNO E EXTERNO ${ }^{1}$
}

\author{
Eliane Pinheiro de Sousa ${ }^{2}$ \\ Antônio Carvalho Campos ${ }^{3}$
}

\begin{abstract}
Resumo: Este artigo objetiva verificar se os acordos comerciais implantados no setor têxtil (Acordo Multifibras, Acordo de Têxteis e Vestuário e liberalização do setor têxtil no comércio mundial) influenciaram a integração entre preços internos e externos do algodão. A metodologia compreende os métodos empregados em séries temporais, como os testes de raiz unitária e de cointegração, de Johansen; decomposição da variância dos erros de previsão; e função impulso-resposta e estimação e análise do modelo vetorial de correção de erro (VEC). Os resultados revelaram que os mercados brasileiro e americano podem ser considerados integrados, quando se analisa a amostra completa. Essa evidência é observada durante o período relativo à vigência do Acordo de Têxteis e Vestuários, $\mathrm{o}$ que indica que variações no preço do algodão, ocorridas em um mercado, foram repassadas ao outro mercado no longo prazo, porém essa transmissão não foi realizada de forma completa, pois a hipótese de perfeita integração entre os mercados foi rejeitada, o que invalida, portanto, a Lei do Preço Único.
\end{abstract}

Palavras-chave: algodão, integração de mercados, Lei do Preço Único, acordos comerciais.

\section{Introdução}

As produções de algodão e de seus manufaturados constituem atividades de grande importância para as economias mundial e brasileira, cujos mercados foram caracterizados pela existência de intervenções

Recebido em: 17/03/09; Aceito em: 31/08/09.

2 Doutoranda em Economia Aplicada na Universidade Federal de Viçosa (UFV) e Professora Adjunta do Departamento de Economia da Universidade Regional do Cariri (URCA). E-mail: pinheiroeliane@ hotmail.com.

3 Ph.D. in Agricultural Economics e Professor Titular do Programa de Pós-Graduação em Economia Aplicada da Universidade Federal de Viçosa (UFV). E-mail: accampos@ufv.br. 
comerciais. Dentre os produtos agrícolas brasileiros, o algodão destacase pela alta incidência de medidas restritivas ao comércio (BARBOSA et al., 2002).

Nesse contexto, é relevante ressaltar que o comércio internacional de produtos do setor têxtil foi regulado por vários acordos, como o Long Term Agreement Regarding International Trade in Cotton Textiles (LTA), que considerava, especificamente, os têxteis de algodão e foi firmado em 1962. Após diversas renegociações, foi substituído pelo Acordo Multifibras (MFA), que passou a vigorar a partir de 1974 e ampliou as regras comerciais, aplicadas ao algodão, para os têxteis de lã e fibras sintéticas. Esse acordo objetivava conter as exportações efetuadas pelos países em desenvolvimento para EUA e Europa. Tal acordo perdurou até o final de 1994, sendo substituído pelo Acordo de Têxteis e Vestuário (ATC), vigente de 1995 a 2004, o qual buscava eliminar o sistema de cotas e integrar o comércio de produtos têxteis e de vestuário às regras da Organização Mundial do Comércio. Porém, a extinção do MFA não representou o fim do protecionismo e das cotas aplicadas ao setor têxtil e vestuário, que foram, gradativamente, eliminadas ao longo de dez anos, período em que vigorou o ATC. Após essa fase de transição, ocorreu, a partir de 2005, a liberalização do setor têxtil no comércio mundial, com a eliminação de restrições quantitativas (NORDAS, 2004; AMARAL, 2006; ARAÚJO, 2006; MELENDRE, 2007; MENDES, 2007; MASHAYEKHI, 2008).

Esses autores preocuparam-se em apresentar uma visão panorâmica das mudanças ocorridas no setor têxtil. Além disso, Amaral (2006) buscou simular os efeitos do fim das cotas, existentes sob o acordo Multifibras, nos sistemas produtivos têxtil e de vestuário brasileiros. Os estudos de Nordas (2004), Araújo (2006) e Mendes (2007) analisaram os impactos da ausência do sistema de cotas no comércio entre os principais mercados consumidores (Estados Unidos e União Europeia) e os países em desenvolvimento. Por sua vez, Melendre (2007) discorreu sobre as consequências da liberalização de produtos têxteis na produção, nos preços e no comércio, assim como as tendências do setor, que também foram discutidas por Mashayekhi (2008). 
Tendo em vista que a implementação desses acordos comerciais gerou mudanças na estrutura de oferta e demanda do setor têxtil e vestuário, refletindo em seus preços, e que o algodão constitui a principal matériaprima da indústria têxtil, é relevante verificar se esses acordos comerciais influenciaram a interação de preços internos e externos do algodão.

Essa questão relativa à integração de preços, nos mercados internos e externos do algodão, foi analisada nos estudos desenvolvidos por Costa e Ferreira Filho (2000), Rochelle (2000); Barbosa et al. (2002); Coelho (2004); Alves e Ferreira Filho (2006); e Sousa e Campos (2008), que verificaram se movimentos nos preços no mercado internacional foram repassados aos preços internos. Além de estimar a elasticidade de transmissão de preços no mercado de algodão, Coelho (2004) também se preocupou em determinar se a abertura comercial, ocorrida no início da década de 90 , efetivamente ocasionou mudança no papel das variáveis externas sobre os preços do algodão no país.

Apesar de tal questão ter sido largamente discutida na literatura econômica, esses estudos supracitados não contemplaram o período específico correspondente à vigência de cada um dos acordos comerciais implantados no setor têxtil. Portanto, os resultados desses trabalhos não refletiram os efeitos de cada acordo, visto que abrangeram horizontes temporais que sombreiam a atuação simultânea de mais de um acordo. Dessa forma, o presente trabalho contribui para verificar se tais acordos geraram mudanças no comportamento das variáveis internacionais sobre os preços do algodão no Brasil, ou seja, se o Acordo Multifibras, em seus últimos cinco anos de atuação, se a adoção do Acordo de Têxteis e Vestuários e se a liberalização no comércio mundial do setor têxtil refletiram o processo de transmissão de preços externos para os preços domésticos do algodão. Ademais, pretende-se mostrar como os preços do algodão brasileiros reagiram a um choque nos preços internacionais, durante a vigência desses acordos comerciais. 


\section{Procedimentos Metodológicos}

\subsection{Referencial teórico}

Este trabalho teve como fundamento teórico a Lei do Preço Único (LPU), a qual estabelece que, em condições de livre concorrência e na ausência de custos de transporte e barreiras oficiais ao comércio, bens idênticos devam ser vendidos por preços equivalentes, independente da moeda em que os preços são cotados (KRUGMAN e OBSTFELD, 2005).

A Lei do Preço Único está relacionada com o processo de arbitragem internacional, o qual, no longo prazo, tende a igualar os preços nos mercados doméstico e internacional. De acordo com Ardeni (1989), a arbitragem de commodities assegura que cada bem possua um preço único, definida em uma unidade corrente comum. Se houver arbitragem, o preço tenderá a subir no mercado com menor preço, em razão do aumento na quantidade demandada, enquanto o preço tenderá a cair no mercado com preço alto, devido ao excesso da quantidade ofertada. Esse processo de arbitragem permanecerá até que os preços, nos dois mercados, sejam igualados.

De acordo com Lima e Burnquist (1997), a LPU expressa relação de equilíbrio de longo prazo entre os preços estabelecidos em dois ou mais mercados distintos. Cada variação no preço em um mercado está associada a uma variação no preço de equilíbrio nos demais mercados relacionados. Essa relação matemática, que caracteriza a LPU, pode ser dada por:

$$
P_{i t}=\alpha+\beta P_{j t}+u_{t}
$$

em que $P_{i t}$ e $P_{j t}$ são preços logaritimizados de determinada commodity, nos mercados de duas regiões i e j, em dado período de 
tempo t; $\alpha$, uma constante (ou intercepto); e o coeficiente $\beta$ é a elasticidade de transmissão de preço entre essas regiões consideradas, de modo que variações de preço na região j serão plenamente transmitidas para a região i, se o valor de $\beta$ for igual a um. Em contrapartida, variações de preço na região j não ocasionarão impactos na região i, se o valor de $\beta$ for igual a zero.

\subsection{Referencial analítico}

Para atender aos objetivos deste trabalho, utilizaram-se testes de raiz unitária e de cointegração, de Johansen; decomposição da variância dos erros de previsão; função impulso-resposta; e estimação e análise do modelo vetorial de correção de erro (VEC).

De acordo com Engle e Granger (1987), quando as variáveis individuais não forem estacionárias, mas uma combinação linear delas for estacionária, essas variáveis serão cointegradas. Para testar a cointegração entre as séries de preços de algodão no Brasil e em Nova Iorque, deve-se inicialmente determinar a ordem de integração, o que é feito por meio do teste de raiz unitária. Neste estudo empregou-se o teste de Dickey-Fuller Aumentado (ADF).

O teste ADF estende-se a um modelo autorregressivo, de ordem superior a um, conforme indicado pela seguinte expressão, descrita por Enders (1995):

$$
\begin{aligned}
& \Delta Y_{t}=\alpha_{0}+\gamma Y_{t-1}+\sum_{i=2}^{p} \beta_{i} \Delta Y_{t-i+1}+\varepsilon_{t} \\
& \text { em que } \gamma=-\left(1-\sum_{i=1}^{p} \alpha_{i}\right) \text { e } \beta_{i}=\sum_{j=i}^{p} \alpha_{j}, \text { sendo } \alpha_{0} \text { o }
\end{aligned}
$$


intercepto; $\gamma$, ordem do modelo autorregressivo que descreve o comportamento da série temporal; $Y$, variável dependente; $\Delta$, operador de diferença; e $\varepsilon_{t}$, estrutura do erro, a qual é idêntica e independentemente distribuída.

A hipótese nula do teste ADF é a existência de uma raiz unitária. Essa hipótese, $H_{0}: \gamma=0$, deverá ser rejeitada, se o valor calculado da estatística t for maior do que o valor crítico de Dickey-Fuller, o que indicará se a série é estacionária; caso contrário, a série será não-estacionária.

Após a identificação da ordem de integração, se todas as séries tiverem a mesma ordem de integração, $\mathrm{I}(\mathrm{d})$, e existir um vetor $\beta(\neq 0)$, em que a combinação linear dessas variáveis seja de ordem $d-b$, $Z_{t}=\beta^{\prime} X_{t} \sim I(d-b), b>0$, então $\mathrm{Y}_{\mathrm{t}}$ será um vetor de cointegração, de ordem $(\mathrm{d}, \mathrm{b})$, denotado por $X_{t} \sim C I(d, b)$, conforme Engle e Granger (1987).

A determinação das relações de cointegração entre as variáveis pode ser feita por vários métodos, e os mais empregados são os de Engle e Granger (1987) e de Johansen (1988). Segundo Bittencourt e Barros (1996), o método de máxima verossimilhança, de Johansen, propõe obter melhores estimativas, testar a presença de mais de um vetor de cointegração e prover testes de razão de verossimilhança para os vetores de cointegração, sob a ótica de sistema de variáveis, o que não é o caso do método de Engle e Granger. Portanto, escolheu-se o método de Johansen, neste trabalho.

A estimação econométrica das relações de preços do algodão entre os mercados brasileiro e americano foi baseada no modelo de autorregressão vetorial (VAR), cuja representação do VAR, de ordem p, é dada por 


$$
Y_{t}=\delta+\Theta_{1} Y_{t-1}+\ldots+\Theta_{p} Y_{t-p}+\varepsilon_{t}
$$

em que cada $\Theta_{j}$ é uma matriz de parâmetros k x k e $\varepsilon_{t}$, um vetor kdimensional de termos ruído branco, com matriz de covariância å.

A equação (3) pode ser reparametrizada por um modelo vetorial de correção de erro (VEC), descrito por

$$
\Delta Y_{t}=\delta+\Gamma_{1} \Delta Y_{t-1}+\ldots+\Gamma_{p-1} \Delta Y_{t-p+1}+\Pi Y_{t-1}+\varepsilon_{t},
$$

em que $\Pi=\gamma \beta$ ', e as combinações lineares $\beta^{\prime} Y_{t-1}$ representam as $r$ relações de cointegração.

Para Harris (1995), citado por Barbosa et al. (2002), a principal vantagem de escrever o sistema pelo modelo de correção de erro é a incorporação de informações tanto de curto quanto de longo prazo, via ajustes no $\Delta Y_{t}$, as quais são dadas pelas estimativas dos parâmetros $\Gamma_{i}$ e $\Pi$.

O número de vetores de cointegração depende do posto ou rank (r) da matriz $\Pi$. De acordo com Verbeek (2000), podem-se ter as seguintes possibilidades: (i) Se $r(\Pi)=0$, esta matriz será nula, logo, todos os componentes de $X_{t}$ serão I(1). Nessa situação, não haverá cointegração, já que não existirá combinação linear entre si que seja estacionária; (ii) Se $r(\Pi)=k$, ou seja, se o posto de $\Pi$ for completo, então as variáveis serão $\mathrm{I}(0)$. Isso significa que qualquer combinação linear entre as variáveis será estacionária em nível. Portanto, não se aplicará a cointegração; e (iii) Se $0<\mathrm{r}<\mathrm{n}$, ter-se-á presença de $r$ vetores de cointegração, que é a possibilidade que interessa neste trabalho. 
Com o intuito de identificar o número de vetores de cointegração presentes neste artigo, empregaram-se os testes do traço e do máximo autovalor. Conforme Enders (1995), o primeiro visa testar a hipótese nula de que o número de vetores de cointegração distintos seja menor ou igual a $r$, contra a hipótese alternativa de que o número desses vetores seja maior do que $r$, enquanto o segundo busca testar a hipótese nula de que o número de vetores de cointegração seja $\mathrm{r}$, contra a hipótese alternativa de existência de $\mathrm{r}+1$ vetores de cointegração. Em termos matemáticos, esses testes podem ser caracterizados por

$$
\lambda_{\text {trace }}(r)=-T \sum_{i=r+1}^{n} \ln \left(1-\lambda_{i}^{\prime}\right)
$$

em que $\hat{\lambda}_{i}$ são os valores estimados das raízes características obtidos da matriz $\Pi$ e T, número de observações; e

$$
\lambda_{\text {max }}(r, r+1)=-T \ln \left(1-\lambda_{r+1}^{\prime}\right) .
$$

Ademais, também se consideraram os testes de hipótese nos parâmetros $\beta$. Segundo Coelho (2004), a existência de um vetor de cointegração não pode ser considerada condição suficiente para determinar a perfeita integração de mercado, nem para garantir que todas as séries participem do equilíbrio de longo prazo. Dessa forma, recomendou que sejam implementados testes de hipóteses nos parâmetros $\beta$.

De acordo com Johansen e Juselius (1990), citados por Coelho (2004), as hipóteses a respeito dos parâmetros $\beta$ apresentam o seguinte formato:

$$
-2 \log Q\left(H_{0}\right)=-T \sum_{i=1}^{r} \log \left[\frac{\left(1-\lambda_{i}^{*}\right.}{\left(1-\lambda_{i}\right.}\right] \text {, para } \mathrm{i}=1, \ldots, \mathrm{r},
$$

em que $T$ é o número de observações; $r$, número de vetores de cointegração; e $\lambda_{i}^{*} e \lambda_{i}$, autovalores do modelo restrito e irrestrito, respectivamente. 
Neste trabalho, testam-se as seguintes hipóteses nulas $\left(\mathrm{H}_{0}\right)$ :

$$
\begin{aligned}
& \beta_{\text {Brasil }}=0 \\
& \beta_{\text {Novalorque }}=0 \\
& \beta_{\text {Brasil }}=\beta_{\text {Novalorque }}
\end{aligned}
$$

Essas hipóteses nulas, descritas em (8) a (10), testam se os mercados brasileiro e norte-americano podem ser considerados integrados no período analisado, enquanto a hipótese contida na equação (10) testa o grau de integração entre os mercados do Brasil e de Nova Iorque.

\subsection{Fonte dos dados}

Os dados empregados neste estudo consistem nas séries de preços do algodão em pluma, mercado físico, no período de janeiro de 1990 a fevereiro de 2009. Para contemplar essa série completa, utilizaram-se esses dados com periodicidade mensal. Ressalta-se que informações de preços com intervalos menores de tempo, por exemplo, diárias quinzenais, só estão disponíveis para períodos mais recentes, o que inviabiliza, pois, a sua adoção. No Brasil, os preços do algodão foram provenientes do banco de dados do Instituto de Pesquisa Econômica Aplicada (IPEADATA, 2009), enquanto os preços do algodão no mercado externo, foram obtidos da série de preços da bolsa de Nova Iorque, coletados no banco de dados da Fundação Getúlio Vargas (FGVDADOS, 2009).

Essas séries de preços foram convertidas em dólares, por toneladas, e logaritimizadas, de modo que os coeficientes obtidos se referem às elasticidades de transmissão de preços. Ademais, também é relevante destacar que tais preços não foram deflacionados, pois, conforme Wang e Tomek (2007), Siqueira (2007) e Cunha (2008), o deflacionamento 
incorpora uma tendência nos dados, logo, não faz sentido incluir uma tendência antes da realização do teste de cointegração.

\section{Resultados e Discussões}

Conforme se observa na representação gráfica, constata-se que essas séries analisadas não apresentaram tendência uniforme ao longo do tempo, o que indica que tais séries de preços não são estacionárias. Ademais, também se verifica que as séries de preços mensais do algodão, no Brasil e em Nova Iorque, movimentaram-se juntas no período considerado. Portanto, é provável que essas séries sejam cointegradas. Para confirmar essas evidências, foram realizados os testes econométricos de raiz unitária, estacionariedade e cointegração.

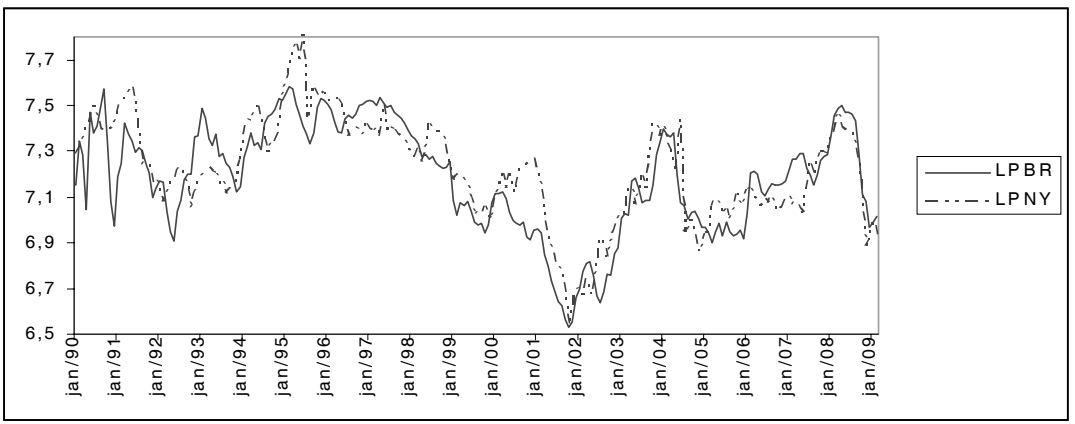

Figura 1 - Comportamento dos preços do algodão no Brasil (LPBR) e em Nova Iorque (LPNY), janeiro de 1990 a fevereiro de 2009.

A partir do teste de raiz unitária, de Dickey-Fuller Aumentado (ADF), verificou-se que as séries em estudo não são estacionárias em nível, visto que a hipótese nula de raiz unitária não pode ser rejeitada para tais séries. Entretanto, quando se analisaram essas séries em primeira diferença, constatou-se que elas passaram a ser estacionárias, pois os valores calculados, em módulo, excederam seus respectivos valores críticos de $5 \%$, nos modelos com intercepto e tendência, apenas com intercepto e sem intercepto e sem tendência (Tabela A1). Isso significa dizer que apenas uma diferenciação foi suficiente para torná-las estacionárias. 
Para confirmar essas evidências, ou seja, verificar se tais séries possuíam, de fato, uma única raiz unitária regular, realizou-se o teste de raízes múltiplas, proposto por Dickey e Pantula (1987) e descrito por Enders (1995). Esse teste, cujos resultados foram omitidos do texto, demonstra que não se pode aceitar a hipótese nula de que essas séries tenham mais de uma raiz unitária. Além disso, para tornarem os testes convencionais de raiz unitária mais robustos, realizou-se o teste HEGY, de raiz unitária sazonal. Tais resultados, omitidos aqui, indicam que a amostra completa analisada não continha raiz unitária sazonal.

Tendo em vista que as séries de preços do algodão, nos mercados brasileiro e americano, são integradas na mesma ordem, neste período analisado buscou-se identificar, por meio de testes de cointegração, se essas séries tinham relacionamento de longo prazo, porém, antes disso, é relevante ressaltar o número de defasagens adotado no modelo VAR. Neste estudo foram consideradas duas defasagens, conforme recomendado pelos critérios de Schwarz e Hannan-Quinn.

Em seguida, realizou-se o teste de cointegração, de Johansen, cujo modelo adotado considera que essas séries analisadas não tenham tendências determinísticas, já que ambas as séries não apresentaram tendência definida, como se observou na Figura 1. Barbosa et al. (2002) consideraram que a constante está incorporada em um termo de correção de erro, ou seja, empregaram o modelo sem tendência determinística e admitiram que as equações de cointegração não tinham intercepto. Essa especificação foi escolhida neste trabalho.

Para identificar o número de vetores de cointegração, realizaram-se os testes do traço e do máximo autovalor (Tabela 1), que demonstraram que as séries de preço do algodão, consideradas neste estudo, continham um único vetor de cointegração, já que a hipótese nula de que não havia nenhum vetor de cointegração foi rejeitada a 5\%. Tais resultados estão de acordo com o estudo de Sousa e Campos (2008), que encontraram relação de cointegração entre o preço do algodão brasileiro e o do algodão no mercado norte-americano, considerando o período de julho de 1996 a janeiro de 2008. 
Tabela 1 - Resultados do teste de cointegração, de Johansen, para as séries mensais de preços do algodão no Brasil e em Nova Iorque, janeiro de 1990 a fevereiro de 2009

\begin{tabular}{ccccc}
\hline $\begin{array}{c}\text { Hipótese } \\
\text { nula }\end{array}$ & $\begin{array}{c}\text { Teste do } \\
\text { Traço }\end{array}$ & $\begin{array}{c}\text { Valor Crítico } \\
(5 \%)\end{array}$ & $\begin{array}{c}\text { Teste do máximo } \\
\text { autovalor }\end{array}$ & $\begin{array}{c}\text { Valor } \\
\text { Crítico (5\%) }\end{array}$ \\
\hline $\mathrm{r}=0$ & $29,1562^{(\mathrm{a})}$ & 12,3209 & $28,9503^{(\mathrm{a})}$ & 11,2248 \\
$\mathrm{r} \leq 1$ & 0,2059 & 4,1299 & 0,2059 & 4,1299 \\
\hline
\end{tabular}

Fonte: Dados da pesquisa.

(a) Indica rejeição da hipótese nula a 5\% de significância.

A equação de cointegração é dada por LPBR $=0,996$ LPNY, o que evidencia que $99,6 \%$ das variações de preços no longo prazo, ocorridas em Nova Iorque, foram transmitidas para o preço do algodão, no Brasil. Resultados similares foram encontrados por Barbosa et al. (2002) e Sousa e Campos (2008), que analisaram a elasticidade de transmissão de preços no mercado brasileiro de algodão, nos períodos de janeiro de 1985 a dezembro de 2000, e de julho de 1996 a janeiro de 2008, respectivamente.

Com base nesse resultado da elasticidade de transmissão do preço do algodão, observa-se a predominância da Lei do Preço Único nesses mercados, já que seu coeficiente foi bem próximo da unidade. No entanto, segundo Barbosa et al. (2002), Coelho (2004) e Sousa e Campos (2008), devem ser impostas restrições aos parâmetros b, para confirmar se essa lei, de fato, prevaleceu, ou seja, para testar a perfeita integração de mercado.

Na Tabela 2, estão os resultados dos testes de hipóteses dos parâmetros $\beta$. A partir desses dados, pode-se inferir que a hipótese nula a respeito dos parâmetros $\beta_{\text {Brasil }}$ e $\beta_{\text {Nova Iorque }}$ pode ser rejeitada, pois seus valores da razão de verossimilhança foram maiores que seus respectivos valores críticos de 5\%, isto é, essas variáveis participaram das relações de longo prazo. Isso significa que variações de preços, ocorridas em um mercado, foram repassadas para outro mercado, no longo prazo. 
Como se constatou que esses mercados são integrados, deve-se testar o grau de integração, ou seja, se essas séries de preços foram perfeitamente integradas. Para tal, testou-se a hipótese nula $\beta_{\text {Brasil }}=\beta_{\text {Nova Iorque }}$, o que indicou sua rejeição, já que os valores da razão de verossimilhança excederam seus respectivos valores críticos de 5\%. Portanto, esses mercados não eram perfeitamente integrados no período considerado, o que contrasta com a existência da Lei do Preço Único para o mercado de algodão.

Tabela 2 - Teste de significância de restrição para o parâmetro de longo prazo (b) do vetor de cointegração, janeiro de 1990 a fevereiro de 2009

\begin{tabular}{lcc}
\hline \multicolumn{1}{c}{ Hipótese nula } & Razão de Verossimilhança & Valor crítico (5\%) \\
\hline$\beta_{\text {Brasil }}=0$ & $28,7407^{(\text {a) }}$ & 3,84 \\
$\beta_{\text {Nova Iorque }}=0$ & $28,7436^{(\text {a) }}$ & 3,84 \\
$\beta_{\text {Brasil }}=\beta_{\text {Nova Iorque }}$ & $28,7442^{(\text {a) }}$ & 3,84 \\
\hline
\end{tabular}

Fonte: Dados da pesquisa. (a) Indica rejeição a 5\% de significância.

Os dados da Tabela 3 revelam que 13,66\% dos desequilíbrios no curto prazo, referentes à trajetória de longo prazo, foram corrigidos a cada mês, o que indica que precisaria, em média, de sete meses para corrigir o desequilíbrio, isto é, tais desequilíbrios transitórios foram corrigidos lentamente.

Tabela 3 - Estimação do VEC referente à variável preço do algodão no Brasil, janeiro de 1990 a fevereiro de 2009

\begin{tabular}{cccc}
\hline Variável explicativa & Coeficiente estimado & Estatística t & Desvio-padrão \\
\hline $\mathrm{u}_{\mathrm{t}-1}$ & $-0,1366$ & $-3,8770$ & 0,0352 \\
\hline
\end{tabular}

Fonte: Dados da pesquisa.

Todos esses resultados discutidos contemplam a série completa analisada de preços mensais do algodão, nos mercados brasileiro e americano, porém o setor têxtil foi regulado por diversos acordos, como Acordo Multifibras, que vigorou entre 1974 a 1994; e Acordo de Têxteis e Vestuários, que prevaleceu entre 1995 a 2004. A partir de 2005, ocorreu a liberalização no comércio mundial do setor. 
Nesse sentido, é relevante replicar os testes realizados para a série completa, em cada um desses períodos, com vistas em verificar se as mudanças ocorridas no setor têxtil repercutiram na integração dos preços internos e externos no mercado de algodão. Para isso, foram consideradas três amostras da série de preços. A primeira considerou o período de janeiro de 1990 a dezembro de 1994, buscando testar os efeitos, nos últimos cinco anos, de atuação do Acordo Multifibras sobre o processo de transmissão de preços externos para os preços nacionais do algodão. Para captar os impactos do Acordo de Têxteis e Vestuários na transmissão de preços internacionais do algodão sobre seus preços domésticos, analisou-se o período correspondente a janeiro de 1995 a dezembro de 2004. Por fim, buscou-se analisar o período de janeiro de 2005 a fevereiro de 2009, que foi marcado pela liberalização no comércio mundial do setor têxtil.

Por meio do teste ADF, verificou-se que a hipótese nula da presença de raiz unitária foi aceita nesses três períodos considerados, logo, essas séries não foram estacionárias em nível, porém passaram a ser estacionárias em primeira diferença (Tabela A2). Da mesma forma realizada para a amostra completa, os testes de raízes múltiplas e de raiz unitária sazonal também foram replicados para cada uma das subamostras consideradas. A partir desses resultados omitidos aqui, constata-se que se pode rejeitar a hipótese nula de existência de mais de uma raiz unitária e que não se verificou a presença de raiz unitária sazonal nas séries LPBR e LPNY, em todas as subamostras analisadas.

Como as séries são integradas de mesma ordem, procede-se à análise de cointegração. Para isso, emprega-se o teste de Johansen, com o intuito de verificar se elas tiveram relacionamento de longo prazo, mas, antes disso, são apresentados os resultados da decomposição da variância dos erros de previsão e as funções de impulso-resposta. 
Tabela 4 - Decomposição da variância dos erros de previsão em percentagem de LPBR e de LPNY, nas três amostras analisadas

\begin{tabular}{ccccccc}
\hline \multirow{2}{*}{ Período } & \multicolumn{5}{c}{ Decomposição da variância dos erros de previsão de LPBR } \\
\cline { 2 - 7 } & LPBR $^{(\text {a) }}$ & LPNY $^{(\text {a) }}$ & LPBR $^{(\text {b) }}$ & LPNY $^{(b)}$ & LPBR $^{(\text {c) }}$ & LPNY $^{(\text {c) }}$ \\
\hline 1 & 100,00 & 0,00 & 100,00 & 0,00 & 100,00 & 0,00 \\
3 & 98,81 & 1,19 & 92,86 & 7,14 & 87,60 & 12,40 \\
6 & 89,88 & 10,12 & 89,73 & 10,27 & 77,19 & 22,81 \\
9 & 82,79 & 17,21 & 88,46 & 11,54 & 75,81 & 24,19 \\
12 & 80,23 & 19,77 & 87,77 & 12,23 & 75,56 & 24,44 \\
\hline Período & \multicolumn{7}{c}{ Decomposição da variância dos erros de previsão de LPNY } \\
\cline { 2 - 7 } & LPBR $^{(\text {a) }}$ & LPNY $^{(\text {a) }}$ & LPBR $^{(\text {b) }}$ & LPNY & LPBR & LPNY $^{(\text {c) }}$ \\
\hline 1 & 1,81 & 98,19 & 2,31 & 97,69 & 9,32 & 90,68 \\
3 & 3,88 & 96,12 & 8,84 & 91,16 & 17,86 & 82,14 \\
6 & 5,18 & 94,82 & 24,26 & 75,74 & 24,62 & 75,40 \\
9 & 5,60 & 94,40 & 36,43 & 63,57 & 26,93 & 73,07 \\
12 & 5,72 & 94,28 & 44,15 & 55,85 & 27,59 & 72,41 \\
\hline
\end{tabular}

Fonte: Dados da pesquisa.

(a) A amostra 1 compreende o período de janeiro de 1990 a dezembro de 1994; ${ }^{\text {(b) }}$ a amostra 2, o período de janeiro de 1995 a dezembro de 2004; $\mathrm{e}^{\text {(c) }}$ a amostra 3, o período de janeiro de 2005 a fevereiro de 2009.

Com relação à variável LPBR, verifica-se que, decorridos 12 meses após um choque não antecipado sobre essa variável, 80,23\%, 87,77\% e $75,56 \%$ de seu comportamento decorreram dela própria, respectivamente, nos períodos em que vigoraram o Acordo Multifibras, o Acordo de Têxteis e Vestuários e a liberalização no comércio mundial do setor têxtil, enquanto o restante foi atribuído à LPNY. Raciocínio análogo pode ser empregado para interpretar a decomposição da variância dos erros de previsão da variável LPNY (Tabela 5).

Quanto aos resultados das funções de impulso-resposta, a Figura 2 mostra que um choque não antecipado nos preços do algodão, no Brasil [diagramas (a), (c), (e)], se desfez mais rapidamente, a partir de 2005, quando foi implementada a liberalização no comércio mundial do setor têxtil [diagrama (e)]. Esse resultado também é observado na série de preços no mercado internacional, denotada por LPNY [diagramas (b), 
(d), (f)], cujo choque de preços foi absorvido, de forma mais rápida, após a liberalização no comércio mundial do setor têxtil [diagrama (f)].

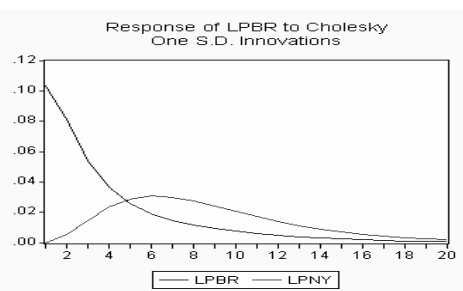

(a)

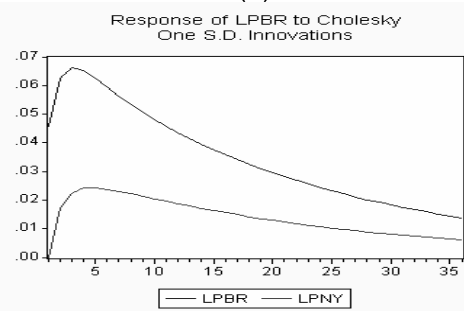

(c)

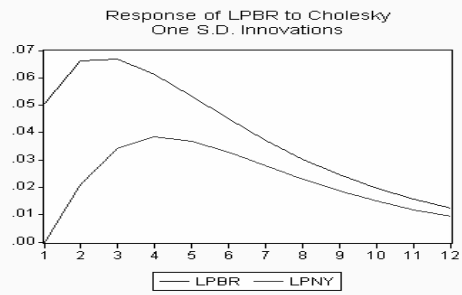

(e)

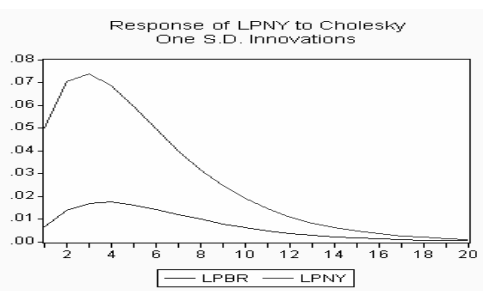

(b)

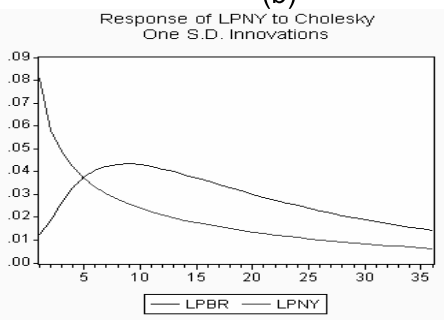

(d)

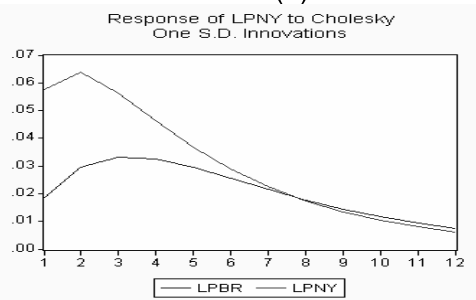

(f)

Figura 2 - Funções de impulso-resposta para as séries mensais de preços do algodão no Brasil (LPBR) e em Nova Iorque (LPNY), nas três amostras analisadas.

Como se pode verificar pelos resultados dos testes do traço e do máximo autovalor, a hipótese nula de que não há nenhum vetor de cointegração não foi rejeitada a 5\%, nas amostras 1 e 3, ou seja, não houve relação de cointegração entre as séries de preços do algodão, nesses períodos considerados. O resultado encontrado na primeira amostra está de acordo 
com o esperado empiricamente, porém tal associação não é verificada na terceira amostra. Para justificar essa divergência, é pertinente destacar as colocações de Costa e Rocha (2009), que ressaltaram que o ranking dos parceiros comerciais de têxteis brasileiros foi diretamente influenciado pelo fim do ATC, visto que os Estados Unidos representavam o principal destino das exportações até 2005, porém, com a eliminação de cotas, a China conquistou boa parte do mercado americano, diminuindo a participação de empresas brasileiras no país. Tais considerações sinalizam o resultado encontrado pelos testes de cointegração na fase pós-liberalização do setor têxtil no comércio mundial.

Tabela 5 - Resultados do teste de cointegração, de Johansen, para as séries mensais de preços do algodão no Brasil e em Nova Iorque, nas três amostras analisadas

\begin{tabular}{|c|c|c|c|c|c|}
\hline Amostras ${ }^{\text {(a) }}$ & $\begin{array}{l}\text { Hipótese } \\
\text { nula }\end{array}$ & $\begin{array}{l}\text { Teste do } \\
\text { Traço }\end{array}$ & $\begin{array}{c}\text { Valor } \\
\text { Crítico }(5 \%)\end{array}$ & $\begin{array}{c}\text { Teste do máximo } \\
\text { autovalor }\end{array}$ & $\begin{array}{c}\text { Valor } \\
\text { Crítico }(5 \%)\end{array}$ \\
\hline \multirow[t]{2}{*}{ Amostra 1} & $\mathrm{r}=0$ & 10,8577 & 12,3209 & 10,6626 & 11,2248 \\
\hline & $\mathrm{r} \leq 1$ & 0,1951 & 4,1299 & 0,1951 & 4,1299 \\
\hline \multirow[t]{2}{*}{ Amostra 2} & $\mathrm{r}=0$ & $16,7672^{(b)}$ & 12,3209 & $15,7819^{\text {(b) }}$ & 11,2248 \\
\hline & $\mathrm{r} \leq 1$ & 0,9853 & 4,1299 & 0,9853 & 4,1299 \\
\hline \multirow[t]{2}{*}{ Amostra 3} & $\mathrm{r}=0$ & 6,8430 & 12,3209 & 6,8415 & 11,2248 \\
\hline & $\mathrm{r} \leq 1$ & 0,0015 & 4,1299 & 0,0015 & 4,1299 \\
\hline
\end{tabular}

Fonte: Dados da pesquisa.

(a) A amostra 1 compreende o período de janeiro de 1990 a dezembro de 1994; a amostra 2, de janeiro de 1995 a dezembro de 2004; e a amostra 3, de janeiro de 2005 a fevereiro de 2009.

(b) Indica rejeição da hipótese nula a 5\% de significância.

Com relação ao período que vigorou o Acordo de Têxteis e Vestuários, ambos os testes indicam presença de um vetor de cointegração. De acordo com Oliveira (1995), conforme estimativas do GATT, espera-se que sejam geradas maiores taxas de crescimento no volume transacionado após a extinção do Acordo Multifibras, a partir de 1995. Dessa forma, se a fase de transição entre a regulamentação do mercado de têxteis e a sua liberalização foi marcada pela tendência de aumento nas transações 
comerciais, então era de esperar que houvesse interação entre parceiros comerciais no período de vigência do ATC. Essa evidência é corroborada pela presença de cointegração entre os mercados têxteis brasileiros e norte-americanos, nessa fase supracitada, cuja equação pode ser expressa por $\mathrm{LPBR}=0,9941 \mathrm{LPNY}$, o que indica que $99,4 \%$ das variações de preços no longo prazo, ocorridas em Nova Iorque nesse período, foram repassadas para o preço do algodão no Brasil, logo, verifica-se que a Lei do Preço Único prevaleceu nesses mercados em tal período considerado. Entretanto, conforme descrito, isso não é suficiente para assegurar a validade dessa lei. Nesse sentido, deveria ter sido testada a perfeita integração de mercado, quando foram impostas restrições aos parâmetros b, cujos resultados estão contidos na Tabela 6 .

Tabela 6 - Teste de significância de restrição sobre o parâmetro de longo prazo (b) do vetor de cointegração, nas três amostras consideradas

\begin{tabular}{|l|l|l|l|}
\hline Amostra & Hipótese nula & Razão de Verossimilhança & Valor crítico (5\%) \\
\hline \multirow{4}{*}{ Amostra 2 } & $\beta_{\text {Brasil }}=0$ & $14,5980^{(b)}$ & 3,84 \\
\cline { 2 - 4 } & $\beta_{\text {Nova Iorque }}=0$ & $14,6477^{(b)}$ & 3,84 \\
\cline { 2 - 4 } & $\beta_{\text {Brasil }}=\beta_{\text {Nova Iorque }}$ & $14,6236^{(b)}$ & 3,84 \\
\hline
\end{tabular}

Fonte: Dados da pesquisa.

(a) A amostra 2 compreende o período de janeiro de 1995 a dezembro de $2004 .{ }^{\text {(b) }}$ Indica rejeição a 5\% de significância.

Os dados da Tabela 6 mostram que a hipótese nula dos parâmetros $\beta_{\text {Brasil }}$ e $\beta_{\text {Nova Iorque }}$ foi rejeitada nesse período. Isso significa que variações nos preços, presentes em um mercado, foram transmitidas para outro mercado no longo prazo, porém essa transmissão não ocorreu de forma completa, visto que os coeficientes das séries de preços, no Brasil e em Nova Iorque, não foram estatisticamente iguais no longo prazo. Assim, constatase que a Lei do Preço Único não foi perfeitamente verificada no mercado de algodão, no período especificado. 


\section{Conclusões}

Os resultados obtidos para a amostra completa de preços do algodão indicam que os mercados brasileiro e americano podem ser considerados integrados. Essa evidência também foi observada durante o período relativo à vigência do Acordo de Têxteis e Vestuários, o que indica que variações no preço do algodão, ocorridas em um mercado, foram repassadas ao de outro mercado, no longo prazo, porém essa transmissão não foi realizada de forma completa, já que a hipótese de perfeita integração entre os mercados foi rejeitada, o que invalida, portanto, a Lei do Preço Único.

Outra inferência que pode ser extraída do estudo é que se constatou, a partir das funções de impulso-resposta, que o equilíbrio de longo prazo demandou menos tempo para ser restabelecido após a liberalização no comércio mundial do setor têxtil, se comparado com os períodos requeridos para absorção dos choques de preços durante a vigência dos Acordos Multifibras e de Têxteis e Vestuários.

Ademais, é importante destacar que este estudo verificou se os acordos comerciais implementados no setor têxtil influenciaram o grau de integração dos mercados interno e externo de algodão, porém foram considerados apenas os preços. Outras variáveis como, por exemplo, taxas de câmbio, que refletem o comportamento dos preços internos, podem ser incorporadas em trabalhos posteriores. 


\section{Referências}

ALVES, L. R. A.; FERREIRA FILHO, J. B. S. Inter-relações de preços dos mercados interno e externo de algodão em pluma. Revista GEPEC. Toledo, PR, v.10, n.1, p. 71-92.

AMARAL, D. F. Efeitos do fim do Acordo Multifibras na produção e no emprego dos setores têxtil e de vestuário no Brasil. In: CONGRESSO DA SOCIEDADE BRASILEIRA DE ECONOMIA E SOCIOLOGIA RURAL, 44, 2006, Fortaleza. Anais... Fortaleza, CE: SOBER, 2006. CD-ROM.

ARAÚJO, C. A. C. L. Análise da cadeia têxtil e de confecções do Estado de Pernambuco e os impactos nela decorrentes do fim do Acordo sobre Têxteis e Vestuário. Recife: PIMES/UFPE, 2006. 146 p. Dissertação (Mestrado em Comércio Exterior e Relações Internacionais) - Universidade Federal de Pernambuco, 2006.

ARDENI, P. G. Does the Law of One Price really hold for commodity prices? American Journal of Agricultural Economics, v. 71, n. 3, p. 661-669, aug., 1989.

BARBOSA, M. Z.; MARGARIDO, M. A.; NOGUEIRA JÚNIOR, S. Análise da elasticidade de transmissão de preços no mercado brasileiro de algodão. Nova Economia. Belo Horizonte, v.12, n.2, p.79-108, jul./ dez.2002.

BITTENCOURT, M. V. L.; BARROS, G. S. C. Relações de preço de frango nas Regiões Sul e Sudeste do Brasil. Revista de Economia e Sociologia Rural. Brasília, v.34, n.3 e 4, p.147-169, 1996.

COELHO, A.B. A cultura do algodão e a questão da integração entre preços internos e externos. Revista de Economia e Sociologia Rural. Rio de Janeiro, v.42, n.1, p.153-169, 2004. 
COSTA, A. C. R.; ROCHA, E. R. P. Panorama da cadeia produtiva têxtil e de confecções e a questão da inovação. BNDES Setorial. Rio de Janeiro, n. 29, p. 159-202, mar. 2009.

COSTA, S. M. A. L.; FERREIRA FILHO, J. B. S. Liberalização comercial no Brasil e integração nos mercados de commodities agrícolas: os mercados de algodão, milho e arroz. Revista de Economia e Sociologia Rural. Rio de Janeiro, v.38, n.2, p.41-70, abr./jun.2000.

CUNHA, D. A. Integração de preços no mercado internacional de café. Viçosa: UFV, 2008. 105p. Dissertação (Mestrado em Economia Aplicada) - Universidade Federal de Viçosa, 2008.

DICKEY, D. A.; PANTULA, S. G. Determining the order of differencing in autoregressive processes. Journal of Business and Economic Statistics, v. 5, n.4, october 1987.

ENDERS, W. Applied Econometric Time Series. Nova York: John Wiley \& Sons, 1995. 433p.

ENGLE, R. F.; GRANGER, C. W. Co-integration and error-correction: representation, estimation and testing. Econometrica, v.55, n.2, p. 251276, 1987.

FUNDAÇÃO GETÚLIO VARGAS - FGVDADOS. Disponível em: http://www.fgvdados.fgv.br. Acesso em: 13/03/2009.

INSTITUTO DE PESQUISA ECONÔMICA APLICADA - IPEA. Disponível em: http://www.ipeadata.gov.br. Acesso em: 13/03/2009.

JOHANSEN, S. Statistical analysis of cointegration vectors. Journal of Economic Dynamics and Control, v.12, p.231-254, 1988.

KRUGMAN, P. R.; OBSTFELD, M. Economia Internacional: teoria e política. São Paulo: Pearson Addison Wesley, 2005. 558p. 
LIMA, S. M. A.; BURNQUIST, H.L. Lei do preço único no mercado internacional: testes empíricos para exportações do complexo soja (grãos e farelo). In: CONGRESSO BRASILEIRO DE ECONOMIA E SOCIOLOGIA RURAL, 35, 1997, Natal. Anais... Natal, RN: SOBER, 1997. CD-ROM.

MASHAYEKHI, M. Training Module on trade in textiles and clothing the post - ATC context. United Nations Publication: New York and Geneva, January 2008, 106p.

MELENDRE, S. Tendencias del comercio internacional de textiles y el vestido. Cuaderno de Negocios Internacionales e Integración. Facultad de Ciencias Empresariales de la Universidad Catolica del Uruguay. Montevideo, n.61-62-63, p. 60-69, 2007.

MENDES, S. M. F. O fim do Acordo de Têxteis e Vestuário: impactos sobre o setor têxtil-vestuário brasileiro. Araraquara: UNESP, 2007. 123 p. Dissertação (Mestrado em Economia) Universidade Estadual Paulista, 2007.

NORDAS, H. K. The global textile and clothing industry post the agreement on textiles and clothing. Discussion Paper n.5. World Trade Organization, Geneva, Switzerland, 2004. 41p.

OLIVEIRA, M. H. Análise conjuntural do setor têxtil. Informe Setorial BNDES n'. 8, 14/11/1995. 5p.

ROCHELLE, T. C. P. Relações de preço no mercado de algodão em pluma e desenvolvimento do mercado futuro de algodão no Brasil. Piracicaba: ESALQ/USP, 2000. 163p. Tese (Doutorado em Ciências) - Universidade de São Paulo, 2000.

SIQUEIRA, K. B. The dynamics of farm milk price formation in Brazil. Viçosa: UFV, 2007. 126 p. Tese (Doutorado em Economia Aplicada) - Universidade Federal de Viçosa, 2007. 
SOUSA, E. P.; CAMPOS, A. C. Transmissão de preços do algodão nos mercados interno e externo. Revista de Política Agrícola. Brasília, DF, v. 17, n. 3, p. 5-16, jul./set. 2008.

VERBEEK, M. A guide to modern econometrics. Chichester: John Wiley \& Sons, 2000. 386p.

WANG, D; TOMEK, W. G. Commodity prices and unit root tests. American Journal of Agricultural Economics, v. 89, n. 4, p. 873-889, 2007.

\begin{abstract}
This article aims at to verify the effects of the trade agreements implanted in the textile sector (Multi-fibre Agreement, Agreement on Textiles and Clothing and liberalization of the textile sector in the world trade) about the integration among the internal and external prices of the cotton of january of 1990 to february of 2009. For that, they were employees the tests for unitary root and Johansen's co-integration; estimation and analysis of and the vector error correction model (VEC) and the exogenicity test. The results revealed that the markets brazilian and american can be considered integrated in all of the analyzed samples, indicating that variations of price of the cotton happened at a market is reviewed to the other market in the long period, however that transmission is not accomplished in a complete way, because the hypothesis of perfect integration between these markets was rejected in all of the studied situations, invalidating, therefore, the Law of One Price.
\end{abstract}

Keywords: cotton, integration of markets, Law of One Price, trade agreements. 


\section{Apêndice}

Tabela A1 - Resultados do teste ADF, em nível e em primeira diferença para as séries mensais de preços do algodão no Brasil (LPBR) e em Nova Iorque (LPNY), nas três amostras analisadas

\begin{tabular}{ccccccccc}
\hline \multirow{2}{*}{$\begin{array}{c}\text { (a) } \\
\end{array}$} & \multicolumn{2}{c}{ LPBR } & \multicolumn{2}{c}{ LPNY } & \multicolumn{2}{c}{ DLPBR } & \multicolumn{2}{c}{ DLPNY } \\
\cline { 2 - 8 } & $\mathrm{t}_{\text {cal }}$ & $\tau_{\alpha=0,05}$ & $\mathrm{t}_{\text {cal }}$ & $\tau_{\alpha=0,05}$ & $\mathrm{t}_{\text {cal }}$ & $\tau_{\alpha=0,05}$ & $\mathrm{t}_{\text {cal }}$ & $\tau_{\alpha=0,05}$ \\
\hline I & $-2,8161$ & -3.4296 & $-2,7908$ & -3.4296 & $-13,3103$ & $-3,4297$ & $-15,0415$ & -3.4296 \\
II & $-2,6529$ & $-2,8740$ & $-2,3423$ & $-2,8740$ & $-13,3443$ & $-2,8740$ & $-15,0697$ & $-2,8740$ \\
III & $-0,3735$ & $-1,9422$ & $-0,3872$ & $-1,9422$ & $-13,3691$ & $-1,9422$ & $-15,0957$ & $-1,9422$ \\
\hline
\end{tabular}

Fonte: Dados da pesquisa.

(a) $\mathrm{O}$ modelo I corresponde ao modelo com intercepto e com tendência; o modelo II, ao modelo com intercepto e sem tendência; e o modelo III, ao modelo sem intercepto e sem tendência.

Tabela A2 - Resultados do teste ADF, em nível e em primeira diferença para as séries mensais de preços do algodão no Brasil (LPBR) e em Nova Iorque (LPNY), nas três amostras analisadas

\begin{tabular}{lccccccc}
\hline Séries & Modelos $^{(\mathrm{a})}$ & \multicolumn{2}{c}{ Amostra ${ }^{(\mathrm{b})}$} & \multicolumn{2}{c}{ Amostra 2 } & \multicolumn{2}{c}{ Amostra $3^{(\mathrm{b})}$} \\
\cline { 2 - 7 } & & $\mathrm{t}_{\text {cal }}$ & $\tau_{\alpha=0,05}$ & $\mathrm{t}_{\text {cal }}$ & $\tau_{\alpha=0,05}$ & $\mathrm{t}_{\text {cal }}$ & $\tau_{\alpha=0,05}$ \\
\hline \multirow{2}{*}{ LPBR } & I & $-2,6052$ & $-3,4921$ & $-2,0242$ & $-3,4483$ & $-1,8502$ & $-3,5064$ \\
& II & $-2,5813$ & $-2,9145$ & $-1,8697$ & $-2,8861$ & $-2,0676$ & $-2,9238$ \\
& III & 0,6288 & $-1,9468$ & $-0,8401$ & $-1,9436$ & 0,1083 & $-1,9478$ \\
\hline \multirow{2}{*}{ LPNY } & I & $-1,7462$ & $-3,4892$ & $-2,3836$ & $-3,4480$ & $-1,4094$ & $-3,5064$ \\
& II & $-1,9531$ & $-2,9126$ & $-1,8301$ & $-2,8859$ & $-1,9477$ & $-2,9238$ \\
& III & 0,4063 & $-1,9465$ & $-0,8586$ & $-1,9435$ & $-0,0385$ & $-1,9477$ \\
\hline \multirow{2}{*}{ DLPBR } & I & $-5,0340$ & $-3,4921$ & $-7,2430$ & $-3,4483$ & $-4,5263$ & $-3,5064$ \\
& II & $-5,1027$ & $-2,9145$ & $-7,2471$ & $-2,8861$ & $-4,3962$ & $-2,9238$ \\
& III & $-5,0951$ & $-1,9468$ & $-7,2203$ & $-1,9436$ & $-4,4413$ & $-1,9478$ \\
\hline \multirow{2}{*}{ DLPNY } & I & $-4,3003$ & $-3,4892$ & $-12,6354$ & $-3,4483$ & $-5,4704$ & $-3,5064$ \\
& II & $-4,2685$ & $-2,9126$ & $-12,6861$ & $-2,8861$ & $-5,2560$ & $-2,9238$ \\
& III & $-4,2860$ & $-1,9465$ & $-12,6526$ & $-1,9436$ & $-5,3145$ & $-1,9478$ \\
\hline
\end{tabular}

Fonte: Dados da pesquisa.

(a) $\mathrm{O}$ modelo I corresponde ao modelo com intercepto e com tendência; o modelo II, ao modelo com intercepto e sem tendência; e o modelo III, ao modelo sem intercepto e sem tendência.

(b) A amostra 1 compreende o período de janeiro de 1990 a dezembro de 1994; a amostra 2, o período de janeiro de 1995 a dezembro de 2004; e a amostra 3, o período de janeiro de 2005 a fevereiro de 2009. 